\title{
Synthesis of New Manganese (II) and Lanthanum (III)Tetrasubtituted Phthalocyanine
}

\author{
Aminu Dauda ${ }^{1}$, Adamu Nurudden ${ }^{2}$ \\ ${ }^{1}$ Department of Chemistry, Faculty of Science, Federal University Dutse, Jigawa State, Nigeria \\ ${ }^{2}$ Department of Industrial Chemistry, Faculty of Science, University of Ilorin, kwara State, Nigeria
}

\begin{abstract}
To synthesized and evaluate the variation of the properties of phthalocyanines with both the position of the substituents and the type of metal used for coordination, tetrasubstituted manganese, and lanthanum, phthalocyanines bearing 7-hydroxycoumarin as substituents were synthesized by the cyclotetramerization reaction of the synthesized 1,3-diiminoisoindoline. The structures of the synthesized compounds were characterized by a combination of ${ }^{1} \mathrm{H} N M R, U V$-Vis, and FT-IR spectrophotometry.
\end{abstract}

Keywords: Phthalocyanine, 1,3-diiminoisoindoline, 7-hydroxycoumarine, Thermal analysis

\section{Introduction}

Phthalocyanines (Pcs) are symmetrical $18 \pi$-electron aromatic macrocycles, closely related to the naturally occuring porphyrins [1]. Phthalocyanines are chemically and thermally stable compounds which can host more than seventy different metal ions in the central cavity [2]. Since their discovery, phthalocyanines have been extensively used as colorants, but more recently they have been employed in different technological areas, i.e. as photoconducting materials, light absorbing layers in recordable CDs, photosensitizers in cancer therapy, and industrial catalysts [3]. Despite the huge number of actual applications, further research is still in dispensable since many other future applications are envisaged. The physical properties and the process ability required for technological applications can be chemically tuned by changing the peripheral substituents and/or the central metal [4]. The possibility of designing and synthesizing unsymmetrically substituted Phthalocyanines may enhance the technological applications of phthalocyanines, i.e. within the field of second-order nonlinear optics. Other feasible chemical manipulation is the alteration of the Phthalocyanine skeleton, that leads to various Phthalocyanine analogues, suchas subphthalocyanines, three-quarter phthalocyaninesand expanded azaporphyrins. More recently, theconstruction of multinuclear and multicomponentPhthalocyanine-based systems is attracting much attention owingto their potential capability of performing complexfunctions, for example as molecular switchesand solar cells, among others. The preparation ofthese complex systems requires the use of modernsynthetic methodologies [5].

The approach in this study focused on the synthesis of inorganic macrocyclic compound (metallated Phthalocyanine) by encapsulating $\mathrm{Mn}$ and La metals inside the void and cage space of phthalocyanine bearing 7hydroxycoumarin substituents on the non-peripheral positions using synthesized 1,3-diiminoisoindoline compound as precursor. Atomic absorption and thermal stability of the new synthesized compound was also investigated.

\section{Materials and Methods}

\subsection{Materials}

All reactions were performed under Argon atmosphere. 7Hydroxy coumarin and 1,8-diazabicyclo [5.4.0] -undec7-ene (DBU), were received from Merck.3-Phthlonitrile from AFG scientific, $\mathrm{Mn}(\mathrm{Ac})_{2} \cdot 4 \mathrm{H}_{2} \mathrm{O}$, and $\mathrm{LaCl}_{3}$, anhydrous dimethylformamide(DMF), Glycerol solution, were obtained from Sigma-Aldrich and used as received without further purification. Other chemicals used were reagent grade.

\subsection{Apparatus}

Melting points of the compounds were determined with Griffin MFB-590.

${ }^{1} \mathrm{H}$ spectra were taken using using Bruker Ultra-shield 400 $\mathrm{MHz}$ with DMSO- $\mathrm{d}_{6}$ as solvents and tetramethylsilane as an internal standard. Transmission FT-IR spectrum of the samples were recorded on an FT-IR spectrophotometer (Perkin Elmer); solid substances were ground with $\mathrm{KBr}$ and pressed to pellets. UV-Vis spectra were recorded on a T80+UV/VIS spectrophotometer. At a heating rate of $10^{\circ} \mathrm{C}$ $\mathrm{min}^{-1}$, TGA was conducted under Argon using a SHIMADZU Thermogravimetric Analyzer TGA-50 Instruments.

\subsection{Synthesis}

\subsubsection{Synthesis of 3-(2-OXO-2H-Chromen-7-YLOXY)} 1,3 Diiminoisoindoline

To a solution of phthalonitrile $1.275 \mathrm{~g}(4.423 \mathrm{mmol})$ in dry methanol $(100 \mathrm{~mL})$ was added sodium methoxide $0.139 \mathrm{~g}$ (2.576 mmol). Anhydrous ammonia was bubbled through the solution under reflux. The course of the reaction was followed by FT-IR spectroscopy, monitoring the $\mathrm{C} \equiv \mathrm{N}$ peak at $2230 \mathrm{~cm}^{-1}$. After the completion of the reaction, the ammonia inlet was closed, and the volume of the reaction mixture was reduced to $10 \mathrm{ml}$ under reduced pressure. The mixture was precipitated with distilled water $(100 \mathrm{ml})$, and the solid was filtered off washed and dried. Yield: $1.108 \mathrm{~g}$ $74 \%$, M.P: $128{ }^{\circ} \mathrm{C},{ }^{1} \mathrm{H}$ NMR (400 MHz, DMSO-d6, $\delta$, 


\section{International Journal of Science and Research (IJSR) \\ ISSN (Online): 2319-7064}

Index Copernicus Value (2015): 78.96 | Impact Factor (2015): 6.391

ppm): $6.50-8.5(\mathrm{~m}, 8 \mathrm{H}, \mathrm{Ar}-\mathrm{H}+\mathrm{H} 2,3)$. FT-IR vmax $/ \mathrm{cm}^{-1}: \mathrm{Ar}-$ $\mathrm{CH}$ (2921) $\mathrm{C}=\mathrm{C}$ (1473) $\mathrm{C}=\mathrm{O}$ (1619) C-O-C (1249).

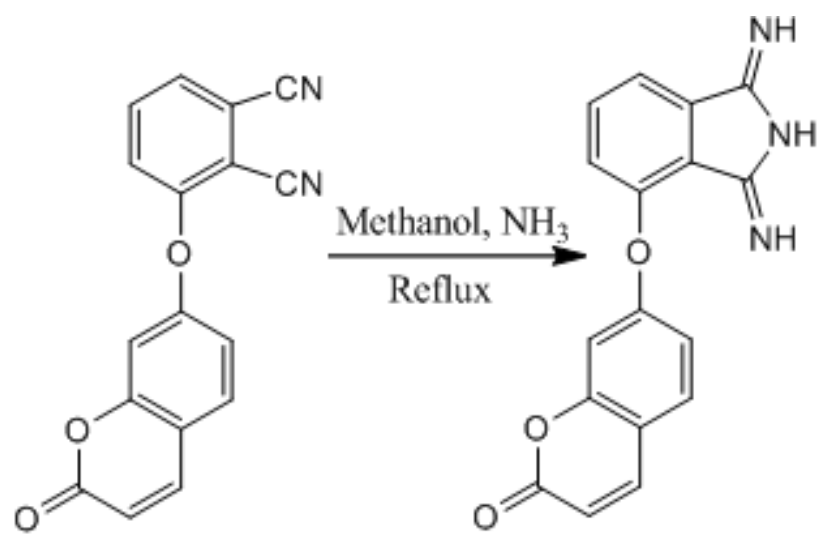

Figure 2.1: Synthesis of 1,3-diiminoisoindoline
2.3.2.1,8,15,22-Tetrakis [3-(oxo-2H-chromen-7-yloxy) coumarin] Manganese (II) Pththalocyanine.

\section{1,3-diiminoisoindoline $\quad(0.200 \quad \mathrm{~g}, \quad 0.655 \quad \mathrm{mmol})$,}

Manganese(II) acetate $\mathrm{Mn}(\mathrm{OAc}) 2 .(0.0736 \mathrm{~g}, 0.300 \mathrm{mmol})$ and1,8-diazabicyclo[ 5.4.0] undec-7- ene (DBU) (3 drops) in DMF/Glycerol $(10 \mathrm{~mL})$ was stirred and heated at reflux temperature under an argon atmosphere for 24 hours. After cooling to room temperature, the reaction mixture was precipitated by adding it drop wise into distilled water $(100 \mathrm{ml})$. The product was precipitated, collected by filtration, purified and washed with distilled water. The green product was dried and weight. Yield: $0.146 \mathrm{~g}, 18 \%$. FT-IR vmax/cm-1: Ar-CH (2929) $\mathrm{C}=\mathrm{C}$ (1599) $\mathrm{C}=\mathrm{O}$ (1727) C-O-C (1274).

Scheme 2.2: Synthesis of Manganese phthalocyanine

\subsubsection{1,8,15,22-Tetrakis [3-(oxo-2H-chromen-7-yloxy) coumarin] Lanthanum (III) Pththalocyanine.}

1,3-diiminoisoindoline $(0.170 \mathrm{~g}, 0.557 \mathrm{mmol})$, lanthanum (III) Chloride $\mathrm{LaCl} 3(0.063 \mathrm{~g}, 0.257 \mathrm{mmol})$ and1,8diazabicyclo [ 5.4.0] undec-7- ene (DBU) (3 drops) in DMF/Glycerol $(10 \mathrm{~mL})$ was stirred and heated at reflux temperature under an argon atmosphere for 24 hours. After cooling to room temperature, the reaction mixture was precipitated by adding it dropwise into distilled water $(100 \mathrm{ml})$. The crude product was precipitated, collected by filtration, purified and washed with distilled water. The green product was dried and weight. Yield:0.145gr, 20\%, M.P: $342^{\circ} \mathrm{C}$. FT-IR vmax/cm-1: Ar-CH (2974) C=C (1611) $\mathrm{C}=\mathrm{O}$ (1710) C-O-C (1245).

Scheme 2.3.synthesis of Lanthanum phthalocyanine

\section{Result and Discussion}

Phthalonitrile derivative was obtained through the nucleophilic substitution reaction between 3- nitro phthalonitrile and 7-Hydroxycourmarin at $80^{\circ} \mathrm{C}$ under Argon atmosphere in dry DMF in the presence of $\mathrm{K}_{2} \mathrm{CO}_{3}$ as a base with $62 \%$ yield. This reaction has been used in the preparation of a variety of ether or thioether substituted phthalonitriles [6,7]. The 1,3-diiminoisoindoline derivative was also obtained as stated in the procedure above. 


\section{International Journal of Science and Research (IJSR) \\ ISSN (Online): 2319-7064 \\ Index Copernicus Value (2015): 78.96 | Impact Factor (2015): 6.391}

Cyclotetramerization of the 1,3-diiminoisoindoline derivative in a high-boiling solvent Glycerol in the presence of a few drops 1,8-diazabicyclo [5.4.0] undec-7-ene DBU as a strong base and anhydrous Metals at reflux temperature under an Argon atmosphere afforded the synthesized phthalocyanines. The route for the synthesis of 1,3diiminoisoindoline and Phthalocyanine compounds were shown above. The characterization of the compounds was carried out by, FT- IR, 1H NMR, UV-vis spectra and TGA. The compounds structures were confirmed by the results of these analyses.

The most important proof of the cyclotetramerization of nitrile groups is the absence of the $-\mathrm{C} \equiv \mathrm{N}$ vibrations at 2230 $\mathrm{cm}^{-1}$ for Phthalocyanines compounds in FT-IR spectra of the substituted Phthalocyanine compounds.

The ground state electronic spectra are especially useful to identify the structure of the phthalocyanines. Generally, UVVis spectra of phthalocyanines show typical electronic spectra with two strong absorption bands known as Q and B bands. The $Q$ band in the visible region at ca. $600-750 \mathrm{~nm}$ is attributed to the $\pi-\pi^{*}$ transition from the highest occupied molecular orbital (HOMO) to the lowest unoccupied molecular orbital (LUMO) of the Pc ring and the B band in the UV region at $300-400 \mathrm{~nm}[8,9]$. The ground state electronic absorption spectra of the non-peripherally tetrasubstituted phthalocyanine complexes showed monomeric behavior evidenced by a single (narrow) Q band, typical of nonaggregated metallophthalocyanine complexes in DMF.

The electronic spectra of Manganese, and Lanthanumphthalocyanine compounds (MnPc,and $\mathrm{LaPc}$ ) in DMF/Glycerol (3:1) are given in figure (3.1 and 3.3) below. The UV-Vis absorption spectra of MnPc, and LaPc, in DMF showed intense Q absorption at $690 \mathrm{~nm}$.

The electronic absorption transitions of these compounds are strongly dependent on the type of the substituent (withdrawing or donating groups) as well as the type of the metal ion and its position (in the centre or on non-peripheral position) [10].

The thermal stability of the compound derivative was checked by TGA. The Phthalocyanine were heated to $700^{\circ} \mathrm{C}$ to determine their degradation temperature. The temperatures at which the phthalocyanine began to exhibit weight loss were $318{ }^{\circ} \mathrm{C}$, and $350{ }^{\circ} \mathrm{C}$, for $\mathrm{MnPc}$, and $\mathrm{LaPc}$, respectively. It could, therefore, be concluded that the Metal Phthalocyanines prepared in this study showed suitably high thermal stability and can be used to prepare dyes for various applications.

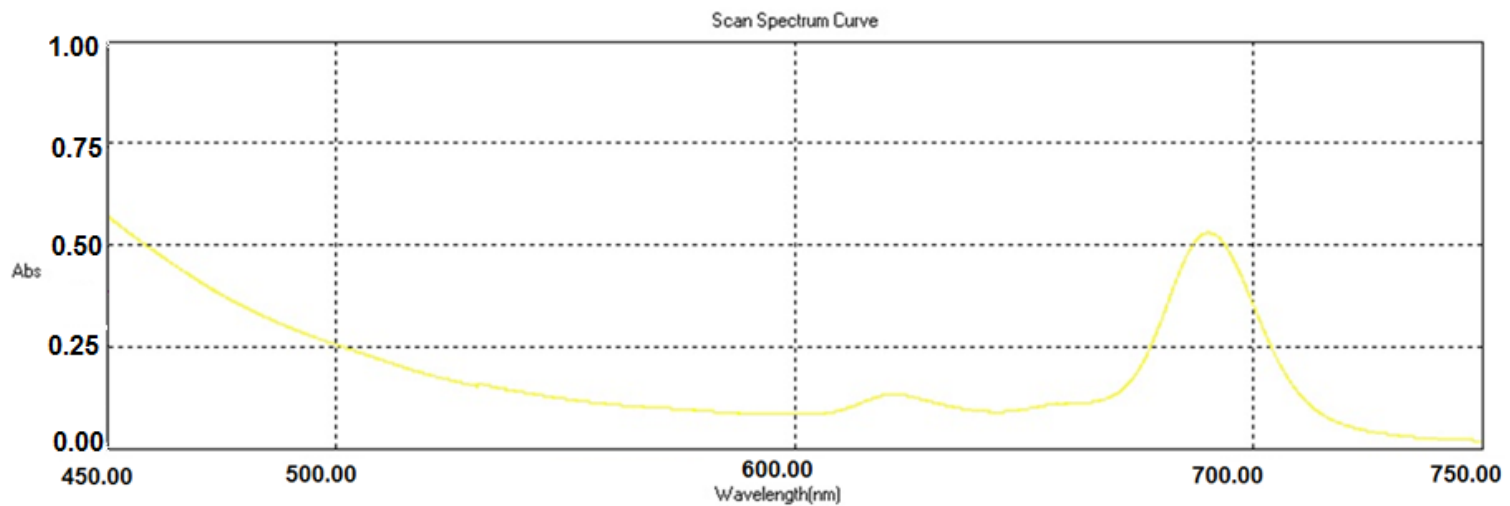

Figure 3.1: UV spectrum of Manganes (II)phthalocyanine

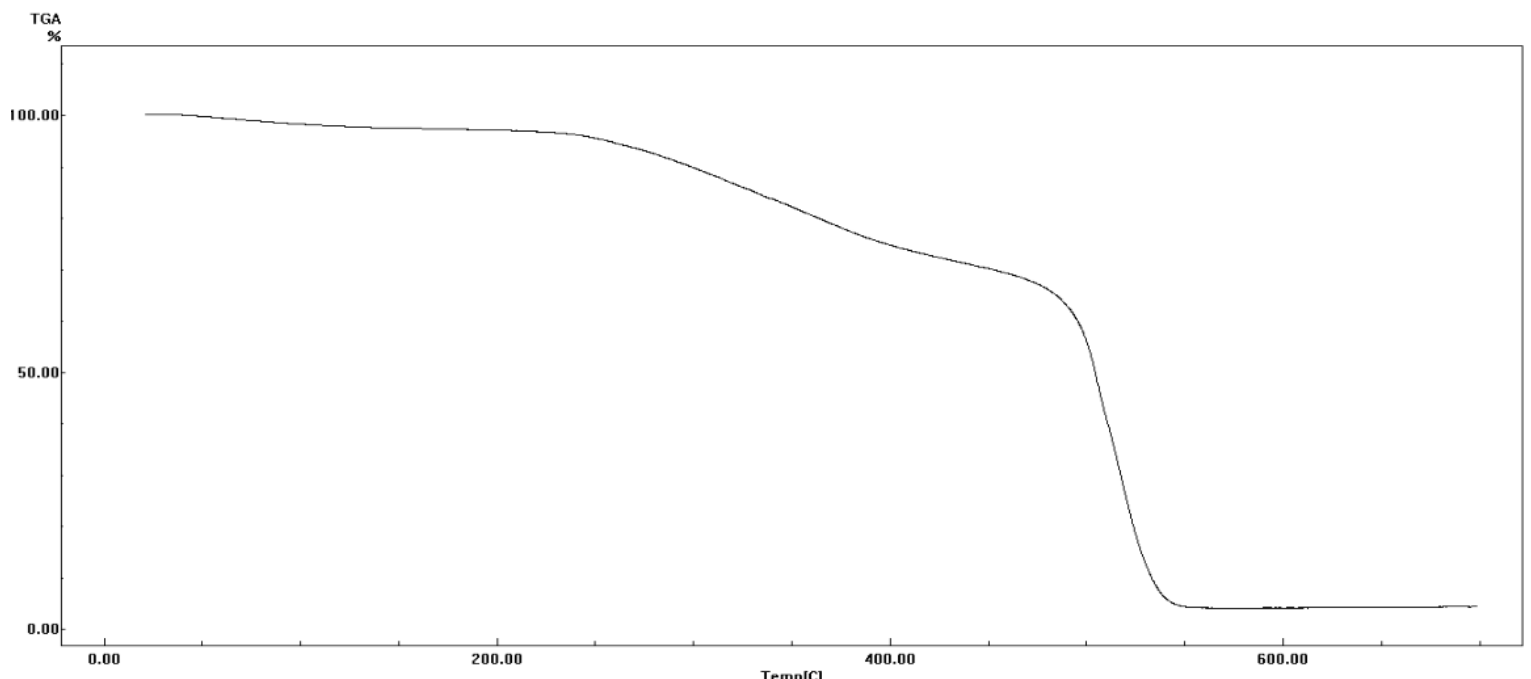

Figure 3.2: TGA of Manganese Phthalocyaninne

Volume 6 Issue 7, July 2017 www.ijsr.net 
International Journal of Science and Research (IJSR)

ISSN (Online): 2319-7064

Index Copernicus Value (2015): 78.96 | Impact Factor (2015): 6.391

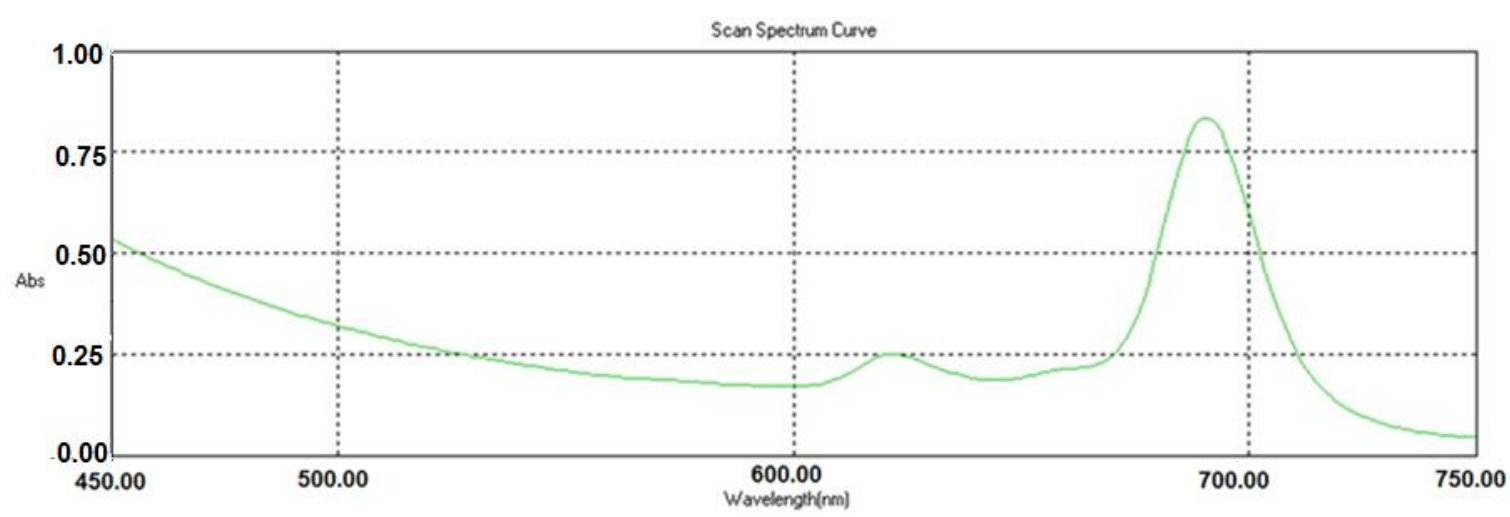

Figure 3.3: UV spectrum of Lanthanum(III)phthalocyanine

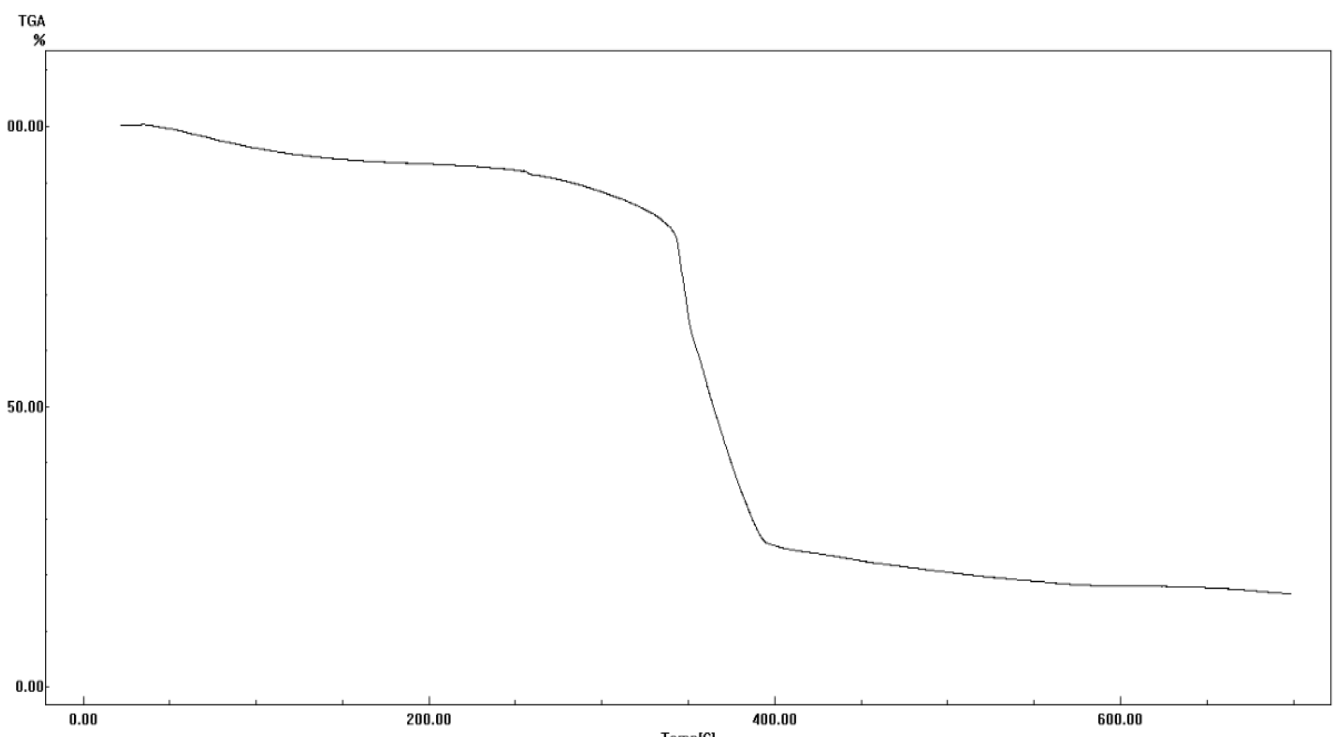

Figure3.4: TGA of Lanthanum Phthalocyaninne

\section{Conclusion}

In conclusion, the present work describes the synthesis and characterization of metal phthalocyanines bearing 7Hydroxy coumarin substituents on the non-peripheral positions, these new complexes were characterized by Electronic absorption spectra, FT-IR spectroscopy and thermal stability. The synthesized phthalocyanine complexes show partial solubility in some organic solvents. such as, THF, DMF and DMSO, the degradation temperature of the compounds were determined and the results shows the synthesized phthalocyanine compounds exhibits a suitably high thermal stability and can be used for various applications.

\section{References}

[1] Haug, A., Harbeck, S., Dini, D., Hanack, M., Cook, M. J., Peisert, H., Chassé, T. 2005. Alkyl chain effects in thin films of substituted phthalocyanines studied using infrared spectroscopy. Applied surface science, 252(1), 139-142.

[2] Calvete, M., Yang, G. Y., Hanack, M. 2004. Porphyrins and phthalocyanines as materials for optical limiting. Synthetic Metals, 141(3), 231-243.

[3] Sharman, W. M., van Lier, J. E. 2005. Synthesis and photodynamic activity of novel asymmetrically substituted fluorinated phthalocyanines. Bioconjugate chemistry, 16(5), 1166-1175..

[4] Liu, D., Zhang, X., You, T. 2014. Electrochemical performance of electrospun free-standing nitrogendoped carbon nanofibers and their application for glucose biosensing. ACS applied materials \& interfaces, 6(9), 6275-6280.

[5] Chow, S. Y., Ng, D. K. 2016. Synthesis of an ABCDType Phthalocyanine by Intramolecular Cyclization Reaction. Organic Letters, 18(13), 3234-3237.

[6] van Staden, J. K. F. 2015. Application of phthalocyanines in flow-and sequential-injection analysis and microfluidics systems: A review. Talanta, 139, 75-88.

[7] Tasso, T. T., Furuyama, T., Kobayashi, N. 2013. Absorption and electrochemical properties of cobalt and iron phthalocyanines and their quaternized derivatives: aggregation equilibrium and oxygen reduction electrocatalysis. Inorganic chemistry, 52(16), 92069215.

[8] Tasso, T. T., Furuyama, T., Kobayashi, N. 2013. Absorption and electrochemical properties of cobalt and iron phthalocyanines and their quaternized derivatives: aggregation equilibrium and oxygen reduction electrocatalysis. Inorganic chemistry, 52(16), 92069215.

[9] Othman, R., Dicks, A. L., Zhu, Z. 2012. Non precious metal catalysts for the PEM fuel cell

Volume 6 Issue 7, July 2017 www.ijsr.net 


\section{International Journal of Science and Research (IJSR) \\ ISSN (Online): 2319-7064}

Index Copernicus Value (2015): 78.96 | Impact Factor (2015): 6.391

cathode. International journal of hydrogen energy, 37(1), 357-372.

[10] Tasso, T. T., Furuyama, T., Kobayashi, N. 2013. Absorption and electrochemical properties of cobalt and iron phthalocyanines and their quaternized derivatives: aggregation equilibrium and oxygen reduction electrocatalysis. Inorganic chemistry, 52(16), 92069215.

[11] Gerken, J. B., Stahl, S. S. 2015. High-Potential Electrocatalytic O2 Reduction with Nitroxyl/NO x Mediators: Implications for Fuel Cells and Aerobic Oxidation Catalysis. ACS central science, 1(5), 234243.

[12] Pandit, S., Khilari, S., Bera, K., Pradhan, D., Das, D. 2014. Application of PVA-PDDA polymer electrolyte composite anion exchange membrane separator for improved bioelectricity production in a single chambered microbial fuel cell. Chemical Engineering Journal, 257, 138-147.

[13] Tasso, T. T., Furuyama, T., Kobayashi, N. 2013. Absorption and electrochemical properties of cobalt and iron phthalocyanines and their quaternized derivatives: aggregation equilibrium and oxygen reduction electrocatalysis. Inorganic chemistry, 52(16), 92069215.

\section{Author Profile}

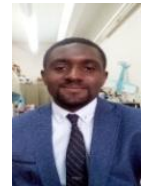

Aminu Dauda was born in Jigawa State, Nigeria. He attended Special Primary School from 1992-1998. He then enrolled at Government Secondary School Mallam Madori for his Junior Secondary school education. He was admitted into Science Secondary School Lautai, Gumel, Jigawa State, from 2002-2004 for his Senior Secondary education. He attended Federal Polytechnic Kazaure, Jigawa State from 2004 to 2006 for his Interim Joint Matriculation board courses, he was later admitted into Prestigious University of Jos, Plateaus State, Nigeria to study Bachelor of Science in Industrial Chemistry from 2007 to 2012. In 2015, he gained admission to study master of science in Inorganic Chemistry at Firat University, Elazig, Turkey. Currently a candidate for the award of Master of Science in Inorganic Chemistry.

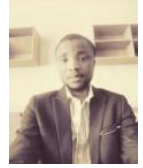

Adamu Nurudeen was born in Zaria, Kaduna State, Nigeria. He attained first school leaving certificate from Katsina State Polytechnic Staff School, Katsinain 2001. He attended Demonstration Secondary School, Okene, Kogi State, Nigeria from 2001 to 2007. He bagged a Bachelor's Degree in Industrial Chemistry from the University of Jos, Jos, Nigeria. Presently in his research year for a Master's degree in Industrial Chemistry in the University of Ilorin, Ilorin, Nigeria. 